\title{
THE ORGANIZATIONAL AND TACTICAL ASPECTS OF INTERACTION OF THE INVESTIGATOR WITH THE EXPERT IN THE ARRANGEMENT AND PRODUCTION OF A FORENSIC MEDICAL EXAMINATION
}

\author{
Andrey A. Medentsov \\ 111 Main State Center for Forensic Medical and Forensic Examinations \\ of the Ministry of Defense of the Russian Federation, Volgograd, Russian Federation
}

Vitaly A. Ruchkin

Volgograd State University, Volgograd, Russian Federation

Ilyas T. Zakharya

Volgograd Academy of the Ministry of Internal Affairs of Russia, Volgograd, Russian Federation

Introduction: the relevance of the research topic lies in the fact that the correct arrangement, as well as the use of the results of forensic medical examinations, opens up wide opportunities in solving a whole range of issues related not only to the resolution of specific cases, but also to the implementation of the tasks facing justice. The purpose of the study: to reveal the distinguishing characteristics and specific features of the interaction between the investigator and the expert in the arrangement and production of a forensic medical examination which could contribute to the resolution of issues in the investigation of crimes. The research objectives: to characterize the activities of the expert in conducting a forensic medical examination; to investigate the legal aspects of the interaction of the investigator with the expert in the arrangement and production of a forensic medical examination; to develop recommendations for improving the interaction between the investigator and the expert. Methods: the methodological framework for the paper consists of the dialectical as well as the specific scientific methods of cognition: comparative-legal, formal-logical, system approaches. Results: the direct focus on improving the work on the interaction of the investigator with the expert in the arrangement and production of a forensic medical examination in the investigation of crimes will allow us in a short time and in full, objectively conduct the expert research in the course of the investigation and crime solution. The organizational, tactical and methodological features of the interaction between the investigator and the expert in the arrangement and production of a forensic medical examination, including the time, place of arrangement and conduct of a forensic medical examination, the preparation of the necessary procedural documents, the tactics of interaction between the investigator and the expert, are revealed. The practical recommendations are given to improve the interaction between the investigator and the expert in the arrangement and production of a forensic medical examination. Conclusions: for $\therefore$ the purpose of productive interaction between the investigator and the expert in the framework of criminal proceedings, -1 the following is necessary: when arranging and conducting a forensic medical examination, there should be the closest contact between the investigator and the forensic expert, which should be of an indirect nature and be carried out in the form of performing their functional duties agreed upon for the purpose of the activity; the efficiency of a forensic medical examination depends primarily on the quality and completeness of the materials submitted, which the investigator $<$ must provide for the forensic expert; the investigator must familiarize the expert with the materials submitted for the $\oplus$ forensic medical examination, agree on their completeness, and, if necessary, provide additional materials (at the request of the forensic expert; the investigator and the forensic expert must interact after the forensic medical examination; for 5 more efficient interaction with the expert, the investigator must include in the crime investigation plan the activities with the participation of the forensic expert with their mandatory approval from the expert himself.

Key words: forensic medical examination, expert, investigator, criminal trial, evidence.

Citation. Medentsov A.A., Ruchkin V.A., Zakharya I.T. The Organizational and Tactical Aspects of Interaction of the Investigator with the Expert in the Arrangement and Production of a Forensic Medical Examination. Legal Concept $=$ Pravovaya paradigma, 2021, vol. 20, no. 2, pp. 82-89. (in Russian). DOI: https://doi.org/10.15688/ lc.jvolsu.2021.2.11 


\title{
ОРГАНИЗАЦИОННЫЕ И ТАКТИЧЕСКИЕ АСПЕКТЫ ВЗАИМОДЕЙСТВИЯ СЛЕДОВАТЕЛЯ И ЭКСПЕРТА ПРИ НАЗНАЧЕНИИ И ПРОИЗВОДСТВЕ СУДЕБНО-МЕДИЦИНСКОЙ ЭКСПЕРТИЗЫ
}

\author{
Андрей Альбертович Меденцов \\ 111 Главный государственный центр судебно-медицинских и криминалистических экспертиз \\ Министерства обороны Российской Федерации, г. Волгоград, Российская Федерация \\ Виталий Анатольевич Ручкин \\ Волгоградский государственный университет, г. Волгоград, Российская Федерация \\ Ильяс Тюлюгенович Захарья \\ Волгоградская академия МВД России, г. Волгоград, Российская Федерация
}

\begin{abstract}
Введение: актуальность темы исследования заключается в том, что правильное назначение, а также использование результатов судебно-медицинских экспертиз открывает широкие возможности в решении целого комплекса вопросов, связанных не только с разрешением конкретных дел, но осуществлением задач, стоящих перед правосудием. Цель исследования: раскрыть особенности и специфические черты взаимодействия следователя и эксперта при назначении и производстве судебно-медицинской экспертизы, которые могли бы способствовать решению вопросов при расследовании преступлений. Задачи исследования: охарактеризовать деятельность эксперта по проведению судебно-медицинской экспертизы; исследовать правовые аспекты взаимодействия следователя и эксперта при назначении и производстве судебно-медицинской экспертизы; разработать рекомендации по совершенствованию взаимодействия следователя и эксперта. Методологическую основу статьи составил диалектический, а также частно-научные методы познания: сравнительно-правовой, формально-логический, системные подходы. Результаты: непосредственная ориентация на совершенствование работы по взаимодействию следователя и эксперта при назначении и производстве судебно-медицинской экспертизы при расследовании преступлений позволит в короткие сроки и в полном объеме объективно провести экспертное исследование в ходе расследования и раскрытия преступлений. Выявлены организационные, тактические и методические особенности взаимодействия следователя и эксперта при назначении и производстве судебно-медицинской экспертизы, включающие в себя время, место назначения и проведения судебно-медицинской экспертизы, оформление необходимых процессуальных документов, тактику взаимодействия следователя и эксперта. Даются практические рекомендации по усовершенствованию взаимодействия следователя и эксперта при назначении и производстве судебно-медицинской экспертизы. Выводы: в целях продуктивного взаимодействия следователя и эксперта в рамках производства по уголовному делу необходимо следующее: при назначении и производстве судебно-медицинской экспертизы между следователем и судмедэкспертом должен быть наиболее тесный контакт, который должен носить опосредованный характер и осуществляться в виде выполнения согласованных по цели деятельности своих функциональных обязанностей; результативность проведения судебно-медицинской экспертизы, прежде всего, зависит от качества и полноты представленных материалов, которые судмедэксперту должен предоставить следователь; следователь обязан ознакомить эксперта с материалами, представляемыми для производства судебно-медицинской экспертизы, согласовать их полноту, а в случае необходимости предоставить дополнительные материалы (по ходатайству судмедэксперта); следователь и судмедэксперт обязаны взаимодействовать и после проведения судебно-медицинской экспертизы; для более эффективного взаимодействия с экспертом следователю необходимо в план расследования преступления включать мероприятия с участием судмедэксперта с их обязательным согласованием у самого эксперта.

Ключевые слова: судебно-медицинская экспертиза, эксперт, следователь, уголовный процесс, доказательства.
\end{abstract}

Цитирование. Меденцов А. А., Ручкин В. А., Захарья И. Т. Организационные и тактические аспекты взаимодействия следователя и эксперта при назначении и производстве судебно-медицинской экспертизы // Legal Concept = Правовая парадигма. -2021 . - Т. 20, № 2. - C. 82-89. - DOI: https://doi.org/10.15688/ lc.jvolsu.2021.2.11 


\section{Введение}

В соответствии с законодательством Российской Федерации под судебно-медицинской экспертизой следует понимать специальный медико-правовой вид деятельности, который направлен на обеспечение предварительного следствия и суда результатами особых исследований, полученных с соблюдением уголовно-процессуального законодательства, осуществляемый судебными экспертами либо врачами, которые привлекаются в целях производства данной экспертизы, лицензированный как отдельный вид деятельности.

Назначение и проведение судебно-медицинских экспертиз осуществляются по многим уголовным делам, и из года в год их количество лишь возрастает. Данное обстоятельство обусловлено научно-техническим прогрессом, что способствует увеличению востребованности судебно-медицинских экспертиз в уголовном процессе для получения ответов на поставленные вопросы. Как справедливо отмечают В.И. Витер, А.Р. Поздеев и А.Ю. Вавилов, по некоторым уголовным делам количество назначаемых и выполненных судебно-медицинских экспертиз по различным направлениям и исследованию объектов порой достигает нескольких десятков и даже сотен [2, с. 171]. Современная теория судебной экспертизы не всегда может давать конкретные ответы на возникающие в практике уголовного судопроизводства вопросы об использовании специальных знаний, в результате чего в правоприменительной деятельности в досудебном уголовном процессе возникают определенные трудности.

\section{Сущность, назначение и производство судебно-медицинской экспертизы в уголовном процессе}

В соответствии с Федеральным законом от 31.05.2001 № 73-Ф3 «О государственной судебно-экспертной деятельности в Российской Федерации» «судебная экспертиза является процессуальным действием, состоящим из проведения исследований и дачи заключения экспертом по вопросам, разрешение которых требует специальных знаний в области науки, техники, искусства или ремесла и ко- торые поставлены перед экспертом судом, судьей, органом дознания, лицом, производящим дознание, следователем, в целях установления обстоятельств, подлежащих доказыванию по конкретному делу».

Сущность судебной экспертизы заключается в проведении исследования иными участниками уголовного процесса в лице эксперта или специалиста предоставляемых в их распоряжение материальных объектов экспертизы (различных предметов, документов, материалов уголовного дела - допустимых вещественных доказательств) с целью установить фактические данные, имеющие значение для правильного разрешения уголовного дела, процессуально оформленных по поручению органов предварительного следствия и судов $[10$, с. $52-$ 53]. Завершается такое исследование дачей экспертного заключения.

Судебно-медицинская экспертиза имеет ряд отличий от других видов экспертиз тем, что подготовка материалов на экспертизу, ее назначение и проведение осуществляются с соблюдением правового регламента и требований, которые содержатся в первую очередь в Федеральном законе «О государственной судебно-экспертной деятельности в Российской Федерации». Уголовно-процессуальным и экспертным законодательством определяются права и обязанности эксперта, субъекта, который назначает судебно-медицинскую экспертизу, а также участников уголовного судопроизводства [1, с. 14]. Например, в соответствии со ст. 28 Федерального закона «О государственной судебно-экспертной деятельности в Российской Федерации» «в государственное судебно-экспертное учреждение должно быть представлено письменное согласие лица подвергнуться судебно-медицинской экспертизе, если судебная экспертиза производится в добровольном порядке».

Представляя собой один из важнейших источников доказательств по уголовным делам, судебно-медицинская экспертиза имеет большое значение в борьбе против преступлений, которые представляют угрозу жизни, здоровью и личному достоинству человека, в рамках уголовного производства [13, с. 34].

Деятельность эксперта по проведению судебно-медицинской экспертизы, как и 
сама экспертиза в уголовном деле, протекает в два этапа:

- на первом этапе проводится экспертиза на стадии предварительного следствия или дознания;

- на втором этапе проводится экспертиза на стадии судебного заседания [8, с. 113].

Рассмотрим первый этап - проведение судебно-медицинской экспертизы на стадии предварительного следствия или дознания.

Если в ходе расследования, на стадиях до возбуждения или после возбуждения уголовного дела, возникает необходимость в судебно-медицинских исследованиях, то органы дознания или предварительного следствия назначают судебно-медицинскую экспертизу [6, с. 93]. Назначение судебно-медицинской экспертизы оформляется специальным процессуальным документом - постановлением, в котором «...отражаются обстоятельства уголовного дела, основания для проведения судебно-медицинской экспертизы, кому поручается проведение судебно-медицинской экспертизы, какие вопросы ставятся на разрешение эксперту, какие материалы и объекты представляются ему для проведения экспертного исследования» [12, с. 39]. После того как эксперт получает постановление дознавателя или следователя, он приступает к экспертным исследованиям предоставленных ему материалов и других данных. При этом представители органов дознания или следствия вправе присутствовать при производстве судебно-медицинской экспертизы. Кроме того, судебный эксперт может присутствовать при допросах, при проведении осмотров места происшествия, при следственных экспериментах и других следственных действиях, с целью получения более точных сведений и материалов, которые необходимы для дачи экспертного заключения. Однако данные действия эксперт может проводить только с разрешения следователя. После окончания исследования судебный эксперт оформляет экспертное заключение в обязательной письменной форме, где описывает процесс и результаты проведенного исследования, а также дает ответы на поставленные перед ним вопросы. Экспертное заключение передается должностному лицу, которое назначило судебно-медицинскую экспертизу.

\section{Особенности взаимодей ствия следователя и эксперта при назначении и производстве судебно-медицинской экспертизы}

В уголовно-процессуальных, криминалистических и психологических научных трудах исследователями для обозначения совместных действий следователя, дознавателя, судей и иных участников уголовно-процессуальной деятельности используются такие концепты, как «взаимоотношения», «взаимодействие», «взаимоконтакты», «коммуникация» и пр. [11, с. 173].

Особую значимость представляют аспекты организации технически грамотного и психологически верного взаимодействия между следователем и иными участниками уголовного процесса в лице эксперта и специалиста для выявления и закрепления фактических данных, которые необходимы для производства материалов уголовных дел различной направленности.

Аспектам взаимодействия следователя и экспертов в рамках расследования преступлений в научной уголовно-процессуальной литературе было уделено немалое внимание (в частности, исследованы процессуальные особенности данной взаимосвязи) [3, с. 47], тем не менее, не все вопросы были освещены - например, тактические и психологические аспекты взаимодействия рассматриваемых участников уголовного процесса разработаны недостаточно.

В ходе предварительного расследования каждый его участник выполняет свои полномочия, однако необходима консолидация усилий для решения поставленных целей. А.П. Когосов совершенно верно подчеркивает, что «...объединение усилий - залог повышения эффективности борьбы с преступностью в целом и предварительного следствия (осуществляемого, конечно же, следователем и никем иным, в частности)» [7, с. 105]. Так, по мнению отечественных исследователей: «...в следственную практику широко внедрены следственно-оперативные группы, которые представляют собой наиболее прогрессивную форму четкого взаимодействия следователя и иных участников расследования преступления (например, оператив- 
ных работников уголовного розыска, сотрудников отделов по борьбе с экономической преступностью, специалистов, экспертов и пр.)» $[4$, c. 35]. Опираясь на ч. 1 ст. 163 УПК РФ, следует отметить, что производство предварительного следствия по уголовному делу в случае его сложности или большого объема может быть поручено следственной группе, о чем выносится отдельное постановление или указывается в постановлении о возбуждении уголовного дела.

В процессе деятельности, осуществляемой следственно-оперативной группой, требуется ролевая дифференциация. Следователю, как руководителю этой группы, подконтрольны все процессуальные действия. Рассматривая психологические аспекты осуществления процессуальной деятельности, к его обязанностям следует отнести и создание условий для работы эксперта (специалиста), и устранение возникающих личностных конфликтов в ходе проведения следственных действий, и решение иных вопросов, препятствующих продуктивному взаимодействию участников следственно-оперативной группы. Особенно это актуально с деятельностью, протекающей в сложных эмоциональных и физических условиях проведения следственного действия.

Наиболее активным взаимодействие следователя и эксперта, как участников уголовного процесса, нам видится при подготовке материалов для исследования. Следователю существенную помощь в рамках производства по уголовному делу могут оказать консультанты по специальным вопросам, например, оказание содействия при отборе образцов для сравнительного исследования и методики его проведения. Е.В. Писарев совершенно верно полагает, что «...важный момент в деятельности следователя при организации данного процессуального действия - подбор и подготовка научно-технических средств» [9, c. 213]. Тем не менее стоит заметить, что применяемые научно-технические средства, методы и приемы при проведении судебномедицинской экспертизы должны быть действительно научными и на практике апробированными.

В рамках производства по уголовному делу немаловажное значение имеет взаимодействие следователя и эксперта при оценке заключения эксперта. Н.Н. Качина отмечает, что правильность оценки следователем этого процессуального документа «...во многом зависит от его объема специальных познаний в определенной области знаний (например, судебной медицине, судебной психиатрии и т. д.), логического мышления, знания всех материалов уголовного дела» [5, с. 42]. $\mathrm{B}$ правоприменительной практике в уголовном судопроизводстве нередки случаи, когда существенные трудности при производстве уголовного дела возникают при оценке следователем результатов проводимых судебно-медицинских экспертиз, которые выполняются посредством применения современных средств, техники и сложных научных методов. Чтобы избегать подобные проблемы в процессе своей профессиональной деятельности, следователю необходимо совместно с экспертом исследовать качество и полноту отданного на экспертизу материала, а также проверить логическую очередность применения и правильность методов исследования, что позволит устранить имеющиеся недочеты и совершенствовать результаты работы в рамках производства по уголовному делу. Кроме того, следователю необходимо акцентировать особое внимание на компетентность судмедэксперта в вопросе передовых методов исследования, безошибочность избрания им техники проведения судебно-медицинской экспертизы, полноту проведения исследований, правильность интерпретации, а также обобщения результатов судебно-медицинской экспертизы.

\section{Заключение}

В целях совершенствования взаимодействия следователя с экспертом необходимо привести ряд рекомендаций.

Во-первых, исходя из специфики взаимодействия следователя и судмедэксперта при назначении и производстве судебно-медицинской экспертизы, между ними должен быть наиболее тесный контакт, который должен носить опосредованный характер и осуществляться в виде выполнения согласованных по цели деятельности своих функциональных обязанностей. Например, если следователь признает целесообразным производство су- 
дебно-медицинской экспертизы, то он должен составить мотивированное постановление (ч. 1 ст. 195 УПК РФ). При этом для формулирования вопросов он должен прибегнуть к помощи судмедэксперта, чтобы вопросы были ясные, четкие и не выходили за пределы компетенции эксперта.

Во-вторых, результативность проведения судебно-медицинской экспертизы, прежде всего, зависит от качества и полноты представленных материалов, которые судмедэксперту должен предоставить следователь. В случае если материалы для производства судебно-медицинской экспертизы находятся в другом месте (например, в архиве МВД) или в силу каких-либо причин не могут быть направлены эксперту, то следователь должен связаться с ним и помочь в получении необходимых документов. При этом следователь должен обеспечить не только сохранность необходимых материалов, но и доставить к месту их нахождения эксперта, а в случае необходимости обеспечить соответствующие условия для работы над ними.

В-третьих, в соответствии с отечественным уголовно-процессуальным законодательством, следователь обязан ознакомить эксперта с материалами, представляемыми для производства судебно-медицинской экспертизы, согласовать их полноту, а в случае необходимости предоставить дополнительные материалы (по ходатайству судмедэксперта в соответствии с п. 2 ч. 3 ст. 57 УПК РФ). Для того чтобы данное взаимодействие было более эффективно, необходимо, чтобы следователь прежде чем предоставить материалы для исследования обратился к эксперту за следующими видами консультаций: относительно назначения судебно-медицинской экспертизы; специалистов и экспертных учреждений, которым может быть поручено производство судебно-медицинской экспертизы; реальных возможностей исследования объекта или субъекта преступления; правильности формулировок и вопросов, которые могут быть поставлены эксперту либо экспертному учреждению.

В-четвертых, следователь и судмедэксперт обязаны взаимодействовать и после проведения судебно-медицинской экспертизы. Полагаем, эксперт должен получить необходимую информацию в результате присутствия при проведении допросов, осмотров документов, воспроизведения обстановки и обстоятельств события. Это, в свою очередь, может служить основанием для экспертных выводов и в то же время будет иметь доказательственное значение.

В-пятых, для более эффективного взаимодействия с экспертом следователю необходимо в план расследования преступления включать мероприятия с участием судмедэксперта с их обязательным согласованием у самого эксперта.

\section{СПИСОК ЛИТЕРАТУРЫ}

1. Винницкий, Л. В. Отдельные положения порядка организации и производства судебно-медицинских экспертиз в государственных судебно-экспертных учреждениях Российской Федерации противоречат действующему уголовно-процессуальному закону / Л. В. Винницкий, Я. Д. Ревенко // Российский следователь. - 2011. - № 14. - С. 12-15.

2. Витер, В. И. Судебная медицина / В. И. Витер, А. Р. Поздеев, А. Ю. Вавилов. - М. : Юрайт, 2020. $-315 \mathrm{c}$.

3. Демидова, Т. В. Взаимодействие следователя с экспертом на стадии подготовки материалов для производства судебных экспертиз / Т. В. Демидова // Вестник экономической безопасности. 2018. - № 1. - С. 46-50.

4. Заславский, Г. И. О присутствии участников процесса при производстве судебно-медицинской экспертизы по уголовным делам / Г. И. Заславский, В. Л. Попов, С. А. Ялышев // Эксперт-криминалист. - 2012. - № 3. - С. 34-37.

5. Качина, Н. Н. Организационные и методологические проблемы оценки заключений судебных медицинских экспертиз / Н. Н. Качина // Медицинское право. - 2012. - № 1. - С. 40-45.

6. Князьков, А. С. Тактические положения взаимодействия следователя и эксперта в ходе подготовки и производства судебной экспертизы / А. С. Князьков // Уголовная юстиция. - 2013. - № 1. - С. 91-95.

7. Когосов, А. П. Некоторые актуальные вопросы экспертной деятельности / А. П. Когосов // Вестник ЮУрГУ. Серия «Право». - 2019. № 2. - C. 103-107.

8. Лазарева, Е. В. Особенности правового статуса субъектов судебно-экспертной деятельности / Е. В. Лазарева // Актуальные проблемы российского права. - 2019. - № 4. - С. 111-117.

9. Писарев, Е. В. Информационное взаимодействие следователя с экспертом / Е. В. Писарев // Вектор науки ТГУ. - 2014. - № 3. - С. 211-214. 
10. Россинская, Е. Р. Судебная экспертиза в гражданском, арбитражном, административном и уголовном процессе / Е. Р. Россинская. - М. : Норма, 2011. $-736 \mathrm{c}$.

11. Светличный, А. А. Проблемы назначения и производства судебно-медицинских экспертиз / А. А. Светличный // Известия ТГУ. Экономические и юридические науки. - 2016. - № 3. - С. 171-177.

12. Сучков, А. В. Анализ постановлений следователей и определений судей о назначении судебно-медицинских экспертиз по уголовным делам, возбужденным в отношении медицинских работников за совершение профессиональных преступлений / А. В. Сучков // Медицинское право. - 2012. № 3. - С. 38-43.

13. Темираев, О. П. Проблемы организации судебно-медицинской экспертизы / О. П. Темираев // Законность. - 2012. - № 8. - С. 33-35.

\section{REFERENCES}

1. Vinnitsky L.V., Revenko Ya.D. Otdelnyye polozheniya poryadka organizatsii i proizvodstva sudebno-meditsinskikh ekspertiz v gosudarstvennykh sudebno-ekspertnykh uchrezhdeniyakh Rossiyskoy Federatsii protivorechat deystvuyushchemu ugolovnoprotsessualnomu zakonu [Separate Provisions of the Order of Organization and Production of Forensic Examinations in State Forensic Experts of the Russian Federation Contradict the Current Criminal Procedure]. Rossiyskiy sledovatel' [Russian Investigator], 2011, no. 14, pp. 12-15.

2. Witer V.I., Pozdeev A.R., Vavilov A.Yu. Sudebnaya meditsina [Forensic Medicine]. Moscow, Yurayt Publ., 2020. 315 p.

3. Demidova T.V. Vzaimodeystviye sledovatelya s ekspertom na stadii podgotovki materialov dlya proizvodstva sudebnykh ekspertiz [Interaction of the Investigator with an Expert at the Preparation of Materials for the Production of Judicial Expertise]. Vestnik ekonomicheskoy bezopasnosti [Bulletin of Economic Security], 2018, no. 1, pp. 46-50.

4. Zaslavsky G.I., Popov V.L., Yalyshev S.A. O prisutstvii uchastnikov protsessa pri proizvodstve sudebno-meditsinskoy ekspertizy po ugolovnym delam [On the Presence of Participants in the Process in the Production of Forensic Medical Examination in Criminal Matters]. Ekspert-kriminalist [Expert Criminalist], 2012, no. 3, pp. 34-37.

5. Kachina N.N. Organizatsionnyye i metodologicheskiye problemy otsenki zaklyucheniy sudebnykh meditsinskikh ekspertiz [Organizational and Methodological Problems Assessing the Conclusions of Judicial Medical Examinations]. Meditsinskoye pravo [Medical Law], 2012, no. 1, pp. 40-45.

6. Knyazkov A.S. Takticheskiye polozheniya vzaimodeystviya sledovatelya i eksperta $\mathrm{v}$ khode podgotovki i proizvodstva sudebnoy ekspertizy [Tactical Provisions of the Interaction of the Investigator and Expert During the Preparation and Production of Forensic Examination]. Ugolovnaya yustitsiya [Criminal Justice], 2013, no. 1, pp. 91-95.

7. Kogosov A.P. Nekotoryye aktualnyye voprosy ekspertnoy deyatelnosti [Some Current Issues of Expertise]. Vestnik YuUrGU. Seriya «Pravo» [Bulletin of SUURSU. Series “Law”], 2019, no. 2, pp. 103-107.

8. Lazareva E.V. Osobennosti pravovogo statusa subyektov sudebno-ekspertnoy deyatelnosti [Features of the Legal Status of Subjects of Forensic Expert Activities]. Aktualnyye problemy rossiyskogo prava [Actual Problems of Russian Law], 2019, no. 4, pp. 111-117.

9. Pisarev E.V. Informatsionnoye vzaimodeystviye sledovatelya s ekspertom [Information Interaction of the Investigator with an Expert]. Vektor nauki TGU [Vector Science TSU], 2014, no. 3, pp. 211-214.

10. Rossinskaya E.R. Sudebnaya ekspertiza v grazhdanskom, arbitrazhnom, administrativnom $i$ ugolovnom protsesse [Judicial Examination in Civil, Arbitration, Administrative and Criminal Process], Moscow, Norma Publ., 2011. 736 p.

11. Svetlichnyj A.A. Problemy naznacheniya i proizvodstva sudebno-meditsinskikh ekspertiz [Problems of Destination and Production of Forensic Medical Examinations]. Izvestiya TGU. Ekonomicheskiye $i$ yuridicheskiye nauki [Izvestiya TSU. Economic and Legal Sciences], 2016, no. 3, pp. 171-177.

12. Suchkov A.V. Analiz postanovleniy sledovateley i opredeleniy sudey o naznachenii sudebno-meditsinskikh ekspertiz po ugolovnym delam, vozbuzhdennym $\mathrm{v}$ otnoshenii meditsinskikh rabotnikov za soversheniye professionalnykh prestupleniy [Analysis of the Decisions of Investigators and Definitions of Judges on the Appointment of Forensic Medical Examinations in Criminal Cases Initiated Against Medical Professionals for Committing Professional Crimes]. Meditsinskoye pravo [Medical Law], 2012, no. 3, pp. 38-43.

13. Temirayev O.P. Problemy organizatsii sudebno-meditsinskoy ekspertizy [Problems of Organization of Forensic Examination]. Zakonnost [Legality], 2012, no. 8, pp. 33-35. 


\section{Information About the Authors}

Andrey A. Medentsov, Candidate of Sciences (Medicine), Associate Professor, Head of Department of Forensic Medical Examination (Volgograd), Branch No. 2 of the Federal State Institution "111 Main State Center for Forensic Medical and Forensic Examinations" of the Ministry of Defense of the Russian Federation, Military Camp No. 1 "Red Barracks", Rokossovskogo St, 117, 400087 Volgograd, Russian Federation, vlg.fil2@bk.ru, https://orcid.org/0000-0003-4327-5074

Vitaly A. Ruchkin, Doctor of Sciences (Jurisprudence), Professor, Department of Forensic Expertise and Physical Materials Science, Volgograd State University, Bogdanova St, 32, 400062 Volgograd, Russian Federation, ruchkin.vitaliy@volsu.ru, https://orcid.org/0000-0003-3891-146X

Ilyas T. Zakharya, Senior Lecturer, Department of Forensic Technology, Volgograd Academy of the Ministry of Internal Affairs of Russia, Istoricheskaya St, 130, 400089 Volgograd, Russian Federation, ils1701@mail.ru, https://orcid.org/0000-0002-9396-9464

\section{Информация об авторах}

Андрей Альбертович Меденцов, кандидат медицинских наук, доцент, заведующий отделением судебно-медицинской экспертизы (г. Волгоград) филиала № 2, 111 Главный государственный центр судебно-медицинских и криминалистических экспертиз Министерства обороны Российской Федерации, военный городок № 1 «Красные казармы», ул. Рокоссовского, 117, 400087 г. Волгоград, Российская Федерация, vlg.fil2@bk.ru, https://orcid.org/0000-0003-4327-5074

Виталий Анатольевич Ручкин, доктор юридических наук, профессор, профессор кафедры судебной экспертизы и физического материаловедения, Волгоградский государственный университет, ул. Богданова, 32, 400062 г. Волгоград, Российская Федерация, ruchkin.vitaliy@volsu.ru, https://orcid.org/0000-0003-3891-146X

Ильяс Тюлюгенович Захарья, старший преподаватель кафедры криминалистической техники, Волгоградская академия МВД России, ул. Историческая, 130, 400089 г. Волгоград, Российская Федерация, ils1701@mail.ru, https://orcid.org/0000-0002-9396-9464 